Key Determinants of Organic Food Consumption: The Case of Olive Oil in Spain

\author{
Manuela Vega-Zamora ${ }^{1}$, Francisco José Torres-Ruiz, \\ and Manuel Parras-Rosa \\ Business Management, Marketing and Sociology Department, University of \\ Jaén, Campus Las Lagunillas, s/n, Jaén 23071, Spain
}

Additional index words. consumer behavior, increasing demand, purchase intent, sustainable consumption, green consumer

\begin{abstract}
The literature on organic consumer behavior has provided some knowledge about the main constructs and variables related to the purchase and consumption of organic foods and could be used to plan strategies to increase demand. However, the recommendations are not clear, varying among different authors, products, and markets; so, it seems necessary to study each case separately. This study aims to isolate the key variables that could influence the purchase of organic olive oil in the Spanish market and to analyze which of these variables have a major effect on the intent to purchase. Using data from a survey of 800 individuals, variables involved in the purchase decision process are included in a linear regression model of latent classes. The results indicate that the product consumption patterns do not respond to a uniform consumption profile but point to a coexistence of groups of people with different propensities to buy and different sensitivities to different commercial stimuli. The main conclusion is that the most effective actions to develop demand should focus on directly linking consumption of the product to consumer benefits such as leading a healthier life, eating a higher-quality product, or enjoying nature, rather than to other variables such as difficulties, perceived costs, or confidence in the certification process.
\end{abstract}

Food scandals such as bovine spongiform encephalopathy ( $\mathrm{mad}$ cow disease), foot-andmouth disease, bird flu, and the proliferation of genetically modified crops have heightened consumer awareness about natural, healthy, safe, high-quality food, which has favored the promotion of food produced through organic farming (Kalogeras et al., 2009; Onyango et al., 2007; Schmid et al., 2007). In other words, the perception of food risks and a loss of confidence in the quality of conventional foods have led to a heightened interest in foods perceived to be healthier (Chen, 2009), such as organic food.

However, although the development of organic farming in Europe is one of the factors that inspired the EU's Common Agricultural Policy and increases in production and consumption have been consistent in recent years, in some countries there is an imbalance between the magnitudes of production and consumption that oblige those countries to export most of their production (Willer and Schaack, 2016), such as in the case of Spain. Because of the weak domestic demand and the favorable political environment

Received for publication 16 Mar. 2018. Accepted for publication 31 May 2018.

This work was supported by the Ministry of Economy, Innovation, Science and Employment, of the Andalusian Regional Government, through the "Strategies for improving the marketing of olive oil" excellence project [AGR-6132].

${ }^{1}$ Corresponding author. E-mail: mvega@ujaen.es. derived from the general interest (from an environmental and social perspective), the Spanish government and producer associations have considered establishing goals for the strategic development of domestic demand [Ministerio de Agricultura y Pesca, Alimentación y Medio Ambiente (MAPAMA), 2007], but the different actions taken to influence that demand are proving only more or less effective at affecting final consumer behavior. Accordingly, the literature on organic food consumer behavior constitutes a framework.

Even though the literature on behavior and the consumption of organic food is relatively large, clear conclusions about how people act cannot be drawn because some controversies related to the basic motivations of consumers still exist. For example, some studies associate organic food consumption with predominantly environmental motives (Becker et al., 2015; Zanoli et al., 2013), whereas others conclude that the motives for consuming this type of food are basically egoistic - related to health, food safety, or the quality or flavor of the food (Aygen, 2012; Chen, 2009; Petrescu et al., 2017; Verain et al., 2015). Similarly, various studies have suggested different strategies to increase demand (Hsu and Chen, 2014; Olivas et al., 2013; Yazdanpanah et al., 2015). All this may be indicative of the existence of different response profiles that vary depending on contextual factors (products, segments, countries, culture, etc.). In this context, although the literature on consumption of organic foods can help to identify the most decisive factors in the demand for certain products, contextual studies are needed to try to explain consumer behavior in each specific case and to identify the most appropriate strategies. Consequently, this study focuses on Spain and on the market for olive oil, given the steadily increasing importance of this product worldwide, its associations with health and the Mediterranean diet, and its strategic significance for Spain, which is the top world producer and has a 50\% market share (International Olive Council, 2017).

Spain's organic farming surface area is the fifth largest in the world and the largest in Europe. However, organic food only has a $1 \%$ market share in Spain, with per capita consumption worth $€ 21$, a far cry from the figures for central and northern European countries such as Switzerland, Austria, Sweden, and Denmark (Lernoud and Willer, 2016; Willer and Schaack, 2016). This suggests that despite the growth trend in the world market, the market for organic products varies widely between countries. Minetti (2002) revealed the existence of different markets depending on the variety of products, the demand structure, and the consumers' organic product knowledge and culture, which means that demand development strategies should accordingly be different.

This study aims to isolate the key factors or variables that could influence the purchase of a specific product (olive oil) in the Spanish market and to analyze which of these variables have a major effect on the intention to purchase. With this goal and an extensive literature review in mind, we isolated the primary factors used to explain consumer behavior related to organic food, and then, we used this information and the results from qualitative preliminary studies about the product to develop indicators to measure each of the explanatory factors' constructs. Finally, the relationship between these explanatory factors and purchase intent was studied. The results could be useful for understanding the demand structure and developing strategies to increase it.

\section{Theoretical Framework}

Models and theories on consumer behavior (Ajzen, 1985, 1991; Ajzen and Fishbein, 1980; Fishbein and Ajzen, 1975), general purchasing behavior, and, in particular, purchasing behavior related to organic food (Gutman, 1982; Magistris and Gracia, 2008; Michaelidou and Hassan, 2008; Rezai et al., 2012; Saleki et al., 2012; Urban et al., 2012; Yadav and Pathak, 2016) were analyzed, then overall consumer behavior toward the environment (Aguirre et al., 2003; Bigné, 1997; Hines et al., 1987) and the results of previous qualitative research into the primary factors explaining organic food consumer behavior in general, and organic olive oil in particular (Vega-Zamora et al., 2014), were drawn on to select the major constructs used to explain behavior.

\section{The major constructs found are as follows:}

Values. The more consistent or coherent the valuation of the attributes of a product 
with the values or interests of the individual, the more favorable the individual's attitude toward that product and the greater the chance they will choose to purchase it (Gutman, 1982). A product is truly relevant when it helps consumers remain consistent with their values (Mulvey et al., 1994). The personal interests of individuals play a part in establishing personal food choice criteria through the values they hold. These values consist of sensory perceptions, monetary considerations, health and nutrition beliefs, convenience, and so on (Fabris, 2010; Furst et al., 1996). In conclusion, individual consumers behave in a way which satisfies certain important personal values so an incongruity between these values and the "characteristics" of a particular product would be an obstacle to consumption. That is to say, values are basic conditions governing consumption of the product and make that product's attributes more or less significant in its choice.

Another important element in understanding the behavior associated with consumption of organic foods is belief (product information, characteristics, uses, etc.). Regardless of the truth of a product's claims, different beliefs may influence consumption related to product characteristics, the consequences of their consumption, their authenticity, etc. In this context, we have found the following:

Trust. Consumer beliefs associated with the veracity and authenticity of a product's organic nature give the product several distinctive features and greater value. Mistrust or consumer skepticism about the authenticity of organic food and its labeling or certification has been recognized as one of the factors that restricts the consumption of organic food (Botonaki et al., 2006; Lea and Worsley, 2005; Padel and Foster, 2005; Roitner-Schobesberger et al., 2008; Schmid et al., 2007; Soares et al., 2008; Tung et al., 2012; Weibel et al., 2012).

Compared beliefs. From the consumer's point of view, compared beliefs are differences between the organic product and the conventional product (safety, naturalness, authenticity, taste, smell, etc.). The consumer's beliefs relate to a product's sensory quality, its ability to preserve the environment, and rural development, etc. Previous literature indicate that beliefs about health and environmental protection associated with the production of this type of food are the most important factors affecting consumer preference (Aygen, 2012; Basarir and Gheblawi, 2012; Chen, 2009; Justin and Jyoti, 2012; Kriwy and Mecking, 2012; Magistris and Gracia, 2008; Padilla et al., 2013; RoitnerSchobesberger et al., 2008; Sangkumchaliang and Huang, 2012; Schmid et al., 2007; Thogersen et al., 2015; Tsakiridou et al., 2008). In addition to these beliefs, others related to food security - such as whether a food is produced without chemical residues or without additives - (Pino et al., 2012), quality, nutrition (Magistris and Gracia, 2008), flavor (Basarir and Gheblawi, 2012;
Roitner-Schobesberger et al., 2008; Schmid et al., 2007), and the contribution to rural development (Padel and Foster, 2005) also influence the consumer's attitude and their decision to purchase organic food. Stolz et al. (2011) conclude that it is likely that the relevance of certain attitudes in determining preferences depends on the beliefs a consumer has in the respective products.

Difficulties. Difficulties are problems faced in the purchase of organic products compared with conventional products. In fact, beliefs associated with the difficulty of purchase are noted in the literature as the primary obstacles to a food's consumption. These difficulties include the high price of organic products compared with conventional products and a product's limited availability and accessibility in the market (Hjelmar, 2011; Marian et al., 2014; RoitnerSchobesberger et al., 2008; Van Loo et al., 2010).

Consequences. The attitude toward the purchase of a product depends on beliefs about the personal impact on the outcomes resulting from that behavior. It focuses on the perceived consequences of a purchase. Knowing how someone feels about buying or using an object turns out to be more valid than merely knowing the consumer's evaluation of the object itself (Ajzen and Fishbein, 1980). Thus, the expectations of the critical outcomes resulting from that behavior are an important antecedent to a behavioral intention.

Intention to purchase. Different variables associated with behavior have an effect on a consumer's intention to purchase, including those mentioned previously. From our point of view, the intention to purchase organic products is a predictor of purchasing behavior and depends on trust, compared beliefs (whether a product has a better taste, is more natural, of higher quality, etc.), difficulties (not easy to find and high price), and consequences (for the individual's health, preservation of environment, etc.). All of these factors are, first and foremost, beliefs. As such, they are subject to outside influences (i.e., through advertising campaigns or by changing the certification process of organic foods), which can have an effect on demand. Values are generally the most stable factor

Table 1. Sample.

\begin{tabular}{ll}
\hline $\begin{array}{l}\text { Scope } \\
\text { Target }\end{array}$ & $\begin{array}{l}\text { National, Spain } \\
\text { Type of interview }\end{array}$ \\
$\begin{array}{l}\text { Urban buyers of olive oil, aged 25-65 } \\
\text { Personal interview, in the street, with a PDA, using a structured } \\
\text { questionnaire. } \\
\text { Sample size }\end{array}$ & $\begin{array}{l}800 \text { valid cases } \\
\text { Random. Restricted by age, gender, and education level } \\
\text { Sample error }\end{array}$ \\
$\begin{array}{l}\text { Demographic profile } \\
\text { Age }\end{array}$ & For global data, $\mathrm{p}=\mathrm{q}=0.5$ and $\mathrm{k}=1.96$, the sample error is $\pm 3.5 \%$. \\
Gender & Mean: $38.33 ;$ sD: 10.74 \\
Education level & Male: $40.1 \% ;$ Female: $59.9 \%$ \\
No. of children & Primary: $14.9 \% ;$ Secondary: $35.1 \%$; University: $50.0 \%$ \\
\hline
\end{tabular}

${ }^{\mathrm{z}}$ The demographic profile is similar across cities because of the prior restrictions set during the planning process.

PDA $=$ personal digital assistant and act as a mediator of, or produce effects on, the rest of the variables. For example, the impact of consumer beliefs associated with the environmental influences of organic products will be significantly smaller in consumers who pay no attention to this factor. The operating aim of this article is to analyze, empirically, the relationship between all of these factors and the consumer's intention to purchase. According to the proposed model, the combination of a consumer's values and beliefs will be an indicator of his/her predisposition to purchase.

\section{Materials and Methods}

Data collection. A survey of urban olive oil buyers older than 25 years and living in Spain was carried out. Data were collected through a structured questionnaire (pretested) that was administered in person on the street, using a personal digital assistant (PDA). A restricted random sample, with quotas by level of education $(50 \%$ of the sample was college educated), age (50\% were aged 35 years or younger), and gender $(60 \%$ were women) was used (Table 1$)$. The literature provides abundant empirical evidence about the influence of these variables on the purchasing behavior and consumption of organic food (Chamberlain et al., 2010; Dimitri and Dettmann, 2012; Donia et al., 2017; Justin and Jyoti, 2012; Lockie et al., 2004; Onyango et al., 2007; Rezai et al., 2012; Roitner-Schobesberger et al., 2008; Tsakiridou et al., 2008; Tung et al., 2012); in our case, however, the subsequent analyses did not reveal significant differences in behavior associated with these variables.

The interviews were conducted in six different cities: Madrid, Barcelona, Seville, Salamanca, Oviedo, and Valencia. The main reason for this choice of cities was their geographical dispersion.

Fieldwork began simultaneously in all cities. A company that designs and conducts market research and opinion campaigns was responsible for carrying out the survey. This company has its own field network and was responsible for programming the PDAs, randomly selecting the respondents (at a 1:3 ratio), conducting the interviews, and processing 
the data files, under the supervision of the authors.

Measurements. Most constructs were measured using a five-point opinion scale. For values, each item measured the importance of a specific value to the consumers. The selection of items was based on previous qualitative research (Vega-Zamora et al., 2014), and an assessment of multiple scales that measure aspects that could possibly be related to food consumption in general and organic food consumption in particular (Botonaki et al., 2006; Fenigstein et al., 1975; Lau et al., 1986; Lea and Worsley, 2005; Lindeman and Väänänen, 2000; Magistris and Gracia, 2008; Magnusson et al., 2003; Maloney et al., 1975; Roitner-Schobesberger et al., 2008; Steptoe et al., 1995; Tsakiridou et al., 2008).

To measure confidence in the certification processes and organic indicators, respondents were asked to rank several aspects related to the production and certification of organic food on a scale of 1 to 5 , where 1 was the lowest level of confidence and 5 the highest.

Beliefs or perceptions about organic extra virgin olive oil were compared with those about conventional, non-organic extra virgin olive oil, using 23 items. These items were selected based on the general beliefs discussed in the literature about organic food and on information obtained from four discussion groups that focused on perceptions of organic foods and olive oil (see VegaZamora et al., 2014). The answers ranged from 1 (clearly conventional) to 5 (clearly

Furthermore, beliefs about the difficulties or problems that consumers face in purchasing organic food in general and organic olive oil in particular were measured using six items. These items were drawn from the mentioned previously, as suggested by Ajzen (2006) and Francis et al. (2004). The scale assesses the extent to which each of the issues identified affects a consumer's decision not to buy organic olive oil.

The scale to measure the consequences of behavior was a five-point Likert scale organic). literature review and the qualitative research

that was developed with reference to the work of Magnusson et al. (2003) but took into account the specific context of this research. Thus, the items selected for this study focused on health, authenticity of the food purchased, social image issues and elitist issues, impacts on the environment, social aspects, and different physical and organoleptic characteristics of the food (its sensory quality).

The consumers' intention to purchase was measured by a semantic differential scale consisting of two items. Chow and Luk (2006), Cox and Locander (1987), Grossbart et al. (1986), Magnusson et al. (2003), and Phelps and Hoy (1996) were used as references in the development of this scale.

All of the scales are included as Supplemental Tables $1-6$.

The reliability of each scale was measured through its internal consistency, by calculating Cronbach's Alpha for each scale (Table 2). In general, high levels of internal consistency allow us to obtain a sum or summary of variables that are good indicators of the constructs found during the analysis. The discriminant validity was also analyzed by calculating the correlations between constructs (Table 3 ). Although the coefficients are significant, the correlations are not high, so presumably, the scales measure different aspects (Hernández et al., 2003).

Data analyses. A linear regression model of latent classes was developed using the software Latent Gold 5.0 (provided by Statistical Innovations; www.statisticalinnovations. com).

In this model, the independent variable was the intention to purchase and the predictors were trust, compared beliefs, consequences, and difficulties. The averages of each scale were used as variables in the model. The whole process relied on a set of underlying assumptions: 1) all variables are likely to be influenced by commercial actions, which gives the model operational logic; 2) the variables used correspond to clear and different constructs. Also, apart from having sufficient theoretical support, the variables are reliable indicators and

Table 2. Reliability

\begin{tabular}{lcc}
\hline Constructs & Number of items & Cronbach's Alpha \\
\hline Values & 14 & 0.845 \\
Trust & 5 & 0.912 \\
Compared beliefs & 23 & 0.940 \\
Difficulties & 6 & 0.849 \\
Consequences & 7 & 0.918 \\
Intention to purchase & 2 & 0.894 \\
\hline
\end{tabular}

independent from each other (Tables 2 and 3); and 3 ) previous research related to organic food consumption reveals the existence of different consumer profiles within organic food consumption (Chen et al., 2014; Kesse-Guyot et al., 2013; Minetti, 2002; Vanhonacker et al., 2013; Vecchio and Annunziata, 2013), each of which has its own motivations.

This third assumption allowed us to infer that instead of developing a global explanatory model, we should develop different models designed for distinct consumer groups based on the relative influence of different factors and the different constructs that developed in these groups. Once this was determined, the question became "How many different models would be developed and on what basis?" The latent class models allowed us to solve this problem empirically. They jointly established the optimal number of classes and the functional relationships between the explanatory variables and the dependent variables (Vermunt and Magidson, 2013).

Regardless of the explanatory variables, the values were introduced as covariates in the model to influence the formation of groups. In this context, another assumption was made: 4) the values profile is directly related to the consumer profile and may affect the relationship between the other variables in the consumer's predisposition to purchase.

In a first phase, different models were developed to determine the optimum number of latent classes. Subsequently, a set of specifications and constraints was established to improve the fit and operation of the model.

\section{Results}

Table 4 shows the fit of different models estimated for different numbers of classes (from 1 to 6). Based on the Bayesian information criterion (BIC) criteria, the model with four latent classes has the best fit. However, a superficial view of the model (Table 5) shows that 1) compared beliefs seem to have no effect, either globally or between classes and 2) that there is a group that does not seem to be affected by the predictors because it shows no intention to purchase the product.

Taking these considerations into account, we developed several restricted models to improve the parsimony and overall fit of the model (Table 6). In the first model, it was established that the beliefs variable has no

Table 3. Pearson correlation coefficients.

\begin{tabular}{|c|c|c|c|c|c|c|}
\hline & Values & Trust & Compared beliefs & Difficulties & Consequences & Intention to purchase \\
\hline Values & 1 & $0.315 * *$ & $0.278 * *$ & 0.040 & $0.434 * *$ & $0.395 * *$ \\
\hline Trust & $0.315 * *$ & 1 & $0.393 * *$ & $0.129 * *$ & $0.487 * *$ & $0.467 * *$ \\
\hline Compared beliefs & $0.278 * *$ & $0.393 * *$ & 1 & -0.006 & $0.579 * *$ & $0.418 * *$ \\
\hline Difficulties & 0.040 & $0.129 * *$ & -0.006 & 1 & $0.080 *$ & -0.036 \\
\hline Consequences & $0.434 * *$ & $0.487 * *$ & $0.579 * *$ & $0.080^{*}$ & 1 & $0.509 * *$ \\
\hline Intention to purchase & $0.395 * *$ & $0.467 * *$ & $0.418 * *$ & -0.036 & $0.509 * *$ & 1 \\
\hline
\end{tabular}

$* P \leq 0.05 ; * * P \leq 0.01$. 
effect on any of the classes. In the second model, group 3's intention to purchase was considered constant, null, and therefore, not dependent on the predictor variables.

Finally, it was observed that in the final solution of this model, another class appeared with low scores and insignificant beta coefficients. Consequently, a restriction-the effect of the predictors on the dependent variable was also 0 in this group (model 3) - was established. At each step, there was a significant and progressive reduction of BIC and associated indicators. Therefore, the final model is considered the most suitable for explaining the consumer's inthere is sufficient theoretical and empirical support to keep these two constraints in the model. This will be explained in the next section.

The final model has acceptable explanatory power $\left(R^{2}=0.81\right)$, although it is not homogeneous between classes (Table 7). The model has a low predictive value for class $1(0.32)$ and a very high value for class 2 (0.98). However, the Wald test suggests that all predictors have explicative capacity, both globally and between classes.

The influence of the difficulties on purchase intention was significantly lower than the influence of the other explanatory variables and the variable that explained the consumers' greater predisposition to buy organic products, thus generating the differences between classes, was consequences. In addition, the inclusion of values as covariates appears to be accurate and significant tention to purchase. It should be noted that

(Wald test $=54.01)$, which is indicative of its utility for a better fit of the model (Table 7).

The first class ( $63.7 \%$ of the sample) shows the highest level of internal heterogeneity (Table 8). This group has the highest variability in the range of food-related values. Overall, it is a group with heterogeneous mean scores for predisposition to purchase. In this class, the consumers' values are not good predictors of group membership and the trust and consequences variables are related to purchase intention but do not explain it precisely. The second class $(12.9 \%)$ has the highest predisposition to purchase organic olive oil. In addition, it has the highest scores on the scale of food-related values. Its main feature is that the only important predictor of intention to purchase is consequences. As a result, the coefficient and high $R^{2}$ allow us to infer that an improvement in perceptions or beliefs about the consequences of using organic olive oil would have a clear effect on the purchase intention of this group.

Groups 3 and 4 (with a set size $23.3 \%$ ) have very low or no intention to purchase and are characterized by the absence of a relationship between the set of predictors and the dependent variable. These groups also have low scores on the scale of values. Both of these facts allow us to infer that in general, there does not seem to be a collective interest in purchasing organic olive oil from a market point of view.

Finally, it should be noted that consumer groups have similar demographic profiles in terms of variables such as age,

Table 4. Preliminary results; setting the number of latent classes in the regression model.

\begin{tabular}{lcccc}
\hline Number of classes & LL & BIC(LL) & Number of parameters & Classification error \\
\hline 1 & -1070.9435 & 2181.7576 & 6 & 0.0000 \\
2 & -1005.2258 & 2103.4828 & 14 & 0.0897 \\
3 & -881.1699 & 1908.5318 & 22 & 0.0903 \\
4 & -829.0140 & 1857.3807 & 30 & 0.1567 \\
5 & -808.2251 & 1868.9637 & 38 & 0.2179 \\
6 & -780.7627 & 1867.1996 & 46 & 0.2871 \\
\hline
\end{tabular}

LL $=$ Log-likelihood statistic; BIC(LL) = Bayesian information criterion based on Log-likelihood.

Table 5. Model of 4 classes (preliminary results).

\begin{tabular}{|c|c|c|c|c|c|c|}
\hline & Class 1 & Class 2 & Class 3 & Class 4 & Overall & \\
\hline$\overline{R^{2}}$ & 0.3827 & 0.4045 & 0.9879 & 0.0000 & 0.8682 & \\
\hline Intention to purchase & Class 1 & Class 2 & Class 3 & Class 4 & Wald & Wald $(=)$ \\
\hline Intercept & 0.7632 & 0.8072 & -0.0897 & 1.0000 & $666.07 * * *$ & $81.82 * * *$ \\
\hline Predictors & Class 1 & Class 2 & Class 3 & Class 4 & Wald & Wald $(=)$ \\
\hline Trust & 0.3396 & 0.1977 & 0.0114 & 0.0000 & $35.49 * * *$ & $34.50 * * *$ \\
\hline Compared beliefs & -0.0349 & 0.2265 & -0.0088 & 0.0000 & 4.15 & 4.15 \\
\hline Consequences & 0.4886 & 0.0414 & 1.0180 & 0.0000 & $1163.41 * * *$ & $1085.47 * * *$ \\
\hline Difficulties & -0.1270 & -0.1557 & 0.0015 & -0.0000 & $15.97 * * *$ & $15.54 * * *$ \\
\hline
\end{tabular}

$* * * P \leq 0.001$. gender, education level, and number of children.

\section{Discussion}

Overall, the results are consistent with our previous assumptions as 1) there are different profiles with different purchasing propensities or intentions; 2) values related to food allow us to identify certain classes of individuals with differentiated purchase intentions; 3 ) for each profile, purchase intention is related to different variables and different influences; and 4) in general, the variables considered are related to purchase intention, although to varying degrees, except for the compared beliefs variable.

However, it is noteworthy that almost a quarter of the sample (classes 3 and 4) showed little or no intention to purchase and were not influenced by the variables considered as predictors in the models. These results are consistent with the low level of consumption of organic olive oil in Spain, where the penetration rate is less than $1 \%$ of households (according to our own estimate, which is based on data from the Food Consumption Panel prepared for the Spanish Ministry of Agriculture and Fishing, Food and Environment). In short, this result indicates that the product consumption patterns do not respond to a uniform consumption profile, but point to a coexistence of groups of people with different propensities to buy and different sensitivities to different commercial stimuli. However, the limited influence of the difficulties variable is striking because it is one of the arguments used by consumers to justify the nonconsumption of organic foods (especially olive oil). In this context, there are at least two possible explanations. First, there may be a high level of perceived costs across all classes. However, this hypothesis is difficult to support because the Wald test shows differences between classes in this predictor.

Another explanation could be a process of rationalization or justification of behavior. Indeed, considering the relative social pressure in favor of consuming organic foods and caring for the environment, it might be thought that the sequence of behavior is not that the perceived difficulties precede the organic non-consumption decision (high costs would imply decisions not to consume), but the opposite: perhaps the decision not to consume is made first, because of an absence of environmental values, and then justified with an argument about high costs or difficulties for individuals. According to this explanation, difficulties or

Table 6. Set of models with 4 classes (restricted).

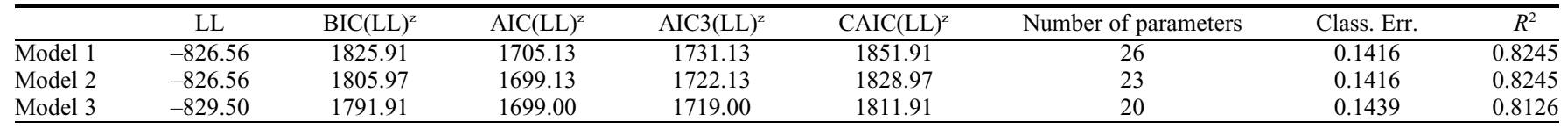

${ }^{\mathrm{z}} \mathrm{BIC}$, AIC, AIC3, and CAIC (based on LL) weight fit and parsimony, adjusting the LL to account for the number of parameters in the model.

$\mathrm{LL}=\mathrm{Log}$-likelihood statistic; BIC $=$ Bayesian information criterion; AIC, AIC3, and CAIC = different Akaike information criteria. 
cost would be a false inhibitor of consumption, inferior to other influencing factors. In relation to this, studies have been published that relate organic food consumption to egoistic motives unconnected with caring for the environment (Aygen, 2012; Chen, 2009; Haghiri et al., 2009; Hamzaoui and Zahaf, 2008; Justin and Jyoti, 2012; Pearson et al., 2011; Roitner-Schobesberger et al., 2008; Vega-Zamora et al., 2011, 2014). In conclusion, it is important to look in this direction to guide decision-making to increase demand. It is possible that it is not as important to manage pricing or distribution as to concentrate resources on other influential factors, such as communicating the consequences of consumption.

Another aspect to consider is the lack of influence of compared beliefs on purchase intent. In this regard, previous literature exists that can serve as a reference to explain this situation. Some authors (Vega-Zamora et al., 2014) have shown that the term "organic" is a heuristic cue or perceptual indicator in the case of olive oil, so that when this term is on the label, the product is perceived as superior to a conventional one. In other words, consumers consider the mere use of the term "organic" as a positive or superior quality. This consideration does not vary between classes and does not influence the purchase decision. It seems that the perceived superiority of a product is a necessary but not sufficient condition for developing the intention to purchase.

In this context, other factors such as confidence in the certification process and, above all, the development of beliefs or attitudes toward the outcomes or benefits of consuming organic olive oil also need to come into play. Indeed, the consequences of behavior seem to be the most influential variable in purchase intention. Consequently, product promotion should not focus solely on describing and differentiating the features of organic olive oil, but needs to link the product's characteristics with direct benefits for the consumer.

On the assumption that most consumers of organic foods reflect a functional-type behavior, where the real motivators are the benefits to consumers (health, quality, and flavor) and more altruistic feelings (preservation of the environment and rural development) come second in their priorities (Magnusson et al., 2003; Michaelidou and Hassan, 2008; Vega-Zamora et al., 2011), it seems that to increase demand, policies should encourage promotions where direct connections between the consumption of organic food and health, quality, tradition, and authenticity are established, as this would have a greater impact than environmental arguments.

\section{Conclusions}

Although the literature on the consumption of organic food is relatively abundant, the variety of results obtained has given rise to some controversy and prevented researchers from making general recommendations to increase the demand for organic foods. Based on the assumption that there is no general pattern of consumption, the use of a regression model of latent classes has proved to be a useful tool for explaining the structure of demand. As a fundamental value, we highlight the possibility of isolating which factors should be considered

Table 7. Final model.

\begin{tabular}{lcccccc}
\hline & Class 1 & Class 2 & Class 3 & Class 4 & Overall & \\
\hline$R^{2}$ & 0.3292 & 0.9871 & 0.0000 & 0.0000 & 0.8126 & \\
Intention to purchase & Class 1 & Class 2 & Class 3 & Class 4 & Wald & Wald $(=)$ \\
Intercept & 0.6044 & -0.1122 & 1.0000 & 1.8989 & $27400.78^{* * *}$ & $688.05^{* * *}$ \\
Predictors & Class 1 & Class 2 & Class 3 & Class 4 & Wald & Wald (=) \\
Trust & 0.3136 & 0.0113 & 0.0000 & 0.0000 & $23.41^{* * *}$ & $23.41^{* * *}$ \\
Comp. beliefs & - & - & - & - & - & - \\
Consequences & 0.4756 & 1.0140 & 0.0000 & 0.0000 & $1879.79^{* * *}$ & $1879.7932^{* * *}$ \\
Difficulties & -0.1069 & 0.0030 & 0.0000 & 0.0000 & $6.54^{* * *}$ & $6.54^{* *}$ \\
Error variances & Class 1 & Class 2 & Class 3 & Class 4 & & \\
Intention to purchase & 0.5448 & 0.0127 & 0.0038 & 0.0619 & & \\
Model for classes & Class 1 & Class 2 & Class 3 & Class 4 & Wald & \\
Intercept & -0.4998 & -3.4249 & 2.5573 & 1.3674 & $31.78^{* * *}$ & \\
Covariates & Class 1 & Class 2 & Class 3 & Class 4 & Wald & \\
Values & 0.4859 & 0.8263 & -0.8135 & -0.4987 & $54.01^{* * *}$ & \\
\hline
\end{tabular}

$* * * P \leq 0.001$.

Table 8. Class profiles.

\begin{tabular}{lllll}
\hline & Class 1 & Class 2 & Class 3 & Class 4 \\
\hline Class size & 0.6373 & 0.1294 & 0.1232 & 0.1101 \\
$\begin{array}{l}\text { Intention to purchase (mean) } \\
\text { Values (covariate) }\end{array}$ & 3.2709 & 4.0088 & 1.0000 & 1.8989 \\
$\quad$ & & & & \\
2.2 .0 & 0.1400 & 0.1046 & 0.4531 & 0.3196 \\
$2.1-2.6$ & 0.2096 & 0.1837 & 0.2277 & 0.3006 \\
$2.7-3.0$ & 0.1928 & 0.1919 & 0.1149 & 0.1598 \\
$3.1-3.5$ & 0.2507 & 0.2408 & 0.1171 & 0.1427 \\
$3.6-4.5$ & 0.2069 & 0.2790 & 0.0872 & 0.0773 \\
Mean & 3.8550 & 3.9626 & 3.3529 & 3.4886 \\
\hline
\end{tabular}

to influence demand and what effect they may have on it. All of this is based on the assumption that there are different consumer profiles that respond uniquely to different stimuli.

The study provides valuable information for businesses, governments, and producer associations, increasing their knowledge of consumer behavior and offering some keys to understanding and developing the demand for organic olive oil. In this context, the main conclusion of this article is that the most effective actions to develop demand would focus on directly linking product consumption to consumer benefits (such as leading a healthier life, eating a higher-quality product, or enjoying nature). This strategy is more appropriate than influencing other beliefs associated with product characteristics, confidence in the certification process, or perceived costs (difficulties). The direct links between consumption and its results, and their higher explanatory power than other constructs, suggest a scenario where the consumer does not engage in intense analytical processing of information related to these products. It seems that the consumer adopts a more functional behavior which is not as interested in absorbing and knowing all the features and processes related to organic food as in their essential utility, the direct benefits of consumption. Consequently, for operational purposes we suggest that direct and simple messages should focus on these, as a basic way of giving the product value and increasing demand. Finally, it should be noted that the impact of such actions is limited because the structure of demand shows groups with no predisposition to purchase that are not influenced by the explanatory factors studied. This makes it possible to reach a smaller, more realistic estimate of the volume and size of the real market for organic olive oils.

In short, we can conclude that there is no single model of purchasing behavior, which means that specific analyses need to be performed for each case. From a practical point of view, we should note that any efforts to increase the demand for organic olive oil should be focused on communicating the direct consequences (in terms of benefits) of consuming it.

The main limitation of this article is that it is a first approach to trying to understand and increase the demand for a product (organic olive oil) in a particular country. The main effect of consequences on demand should be analyzed in other products and markets, particularly in those where consumption is higher. Also, if it is assumed that establishing direct links between consumption and its consequences or benefits is very important, it would be interesting to study which specific messages can be most effective. Similarly, the analysis can be enriched by introducing other types of variables, for example, psychographic variables (involvement, degree of knowledge, etc.), which are most helpful for decision-making. 


\section{Literature Cited}

Aguirre, M.S., C. Aldamiz-Echevarría, J. Charterina, and A. Vicente. 2003. El consumidor ecológico. Un modelo de comportamiento a partir de la recopilación y análisis de la evidencia empírica. Distribución y Consumo 67:24-39.

Ajzen, I. 1985. From intentions to actions: A theory of planned behaviour, p. 11-39. In: J. Kuhl and J. Beckmann (eds.). Action-control: From cognition to behaviour. Springer-Verlag, Berlin, Germany.

Ajzen, I. 1991. The theory of planned behavior. Organ. Behav. Hum. Decis. Process. 50(2): 179-211.

Ajzen, I. 2006. Constructing a TpB questionnaire: Conceptual and methodological considerations. 15 Feb. 2018. <http://www-unix.oit. umass.edu/ aizen/pdf/tpb.measurement.pdf $>$.

Ajzen, I. and M. Fishbein. 1980. Understanding attitudes and predicting social behavior. Prentice-Hall, Englewood Cliffs, NJ.

Aygen, F.G. 2012. Attitudes and behavior of Turkish consumers with respect to organic foods. Intl. J. Bus. Soc. Sci. 3(18):262-273.

Basarir, A. and M.S. Gheblawi. 2012. Analyzing demand and consumers willingness to pay for organic fruits and vegetables. J. Food Agr. Environ. 10(3-4):86-91.

Becker, N., T. Tavor, L. Friedler, and P. Bar. 2015. Two stages decision process toward organic food: The case of organic tomatoes in Israel. Agroecol. Sustainable Food Syst. 39(3):342361.

Bigné, J.E. 1997. El consumidor verde: Bases de un modelo de comportamiento. Esic Market 96:29-43.

Botonaki, A., K. Polymeros, E. Tsakiridou, and K. Mattas. 2006. The role of quality certification on consumers' food choices. Brit. Food J. 108 (2-3):77-90.

Chamberlain, A., K. Kelley, and J. Hyde. 2010. Consumer purchasing behavior and attitudes toward locally-grown and certified organic food products in the Mid-Atlantic region. HortScience 45:S69-S70.

Chen, M.F. 2009. Attitude toward organic foods among Taiwanese as related to health consciousness, environmental attitudes, and the mediating effects of a healthy lifestyle. Brit. Food J. 111(2-3): 165-178.

Chen, J., A. Lobo, and N. Rajendran. 2014. Drivers of organic food purchase intentions in mainland china-evaluating potential customers' attitudes, demographics and segmentation. Intl. J. Consum. Stud. 38(4):346-356.

Chow, Ch.W.C. and Ch.L. Luk. 2006. Effects of comparative advertising in high- and lowcognitive elaboration conditions. J. Advert. 35(2):55-67.

Cox, D.S. and W.B. Locander. 1987. Product novelty: Does it moderate the relationship between ad attitudes and brand attitudes? J. Advert. 16(3):39-44.

Dimitri, C. and R.L. Dettmann. 2012. Organic food consumers: What do we really know about them? Brit. Food J. 114(8-9):1157-1183.

Donia, E., A.M. Mineo, D. Cesarini, and F. Sgroi. 2017. Food consumer models: The case of the responsible consumer. Qual. Access Success 18(161):145-148.

Fabris, G. 2010. Il nuovo consumatore: Verso il postmoderno. FrancoAngeli, Milano, Italy.

Fenigstein, A., M.F. Scheier, and A.H. Buss. 1975. Public and private self-consciousness: Assessment and theory. J. Consult. Clin. Psychol. 43(4): $522-527$.
Fishbein, M. and I. Ajzen. 1975. Belief, attitude, intention and behavior: An introduction to theory and research. Addison-Wesley, Reading, MA.

Francis, J.J., M.P. Eccles, M. Johnston, A. Walker, J. Grimshaw, R. Foy, E.F.S. Kaner, L. Smith, and D. Bonetti. 2004. Constructing questionnaires based on the theory of planned behavior. A manual for health services researchers. Centre for Health Serv. Res., Univ. Newcastle, Newcastle upon Tyne, UK.

Furst, T., M. Connors, C.A. Bisogni, J. Sobal, and L.W. Winter. 1996. Food choice: A conceptual model of the process. Appetite 26(3):247-265

Grossbart, S., D.D. Muehling, and N. Kangun 1986. Verbal and visual references to competition in comparative advertising. J. Advert. 15(1):10-23.

Gutman, J. 1982. A means-end chain model based on consumer categorization processes. J. Mktg. 46(2):60-72.

Haghiri, M., J.E. Hobbs, and M.L. McNamara. 2009. Assessing consumer preferences for organically grown fresh fruit and vegetables in Eastern New Brunswick. Intl. Food Agribus. Mgt. Rev. 12(4):81-100.

Hamzaoui, L. and M. Zahaf. 2008. Decision making process of community organic food consumers: An exploratory study. J. Consum. Mktg. 25(2):95-104.

Hernández, R., C. Fernández, and P. Baptista 2003. Metodología de la investigación. 3rd ed. McGraw Hill, Ciudad de Mexico, Mexico.

Hines, J.M., H.R. Hungerford, and A.N. Tomera 1987. Analysis and synthesis of research on responsible environmental behavior: A metaanalysis. J. Environ. Educ. 18(2):1-8.

Hjelmar, U. 2011. Consumers' purchase of organic food products. A matter of convenience and reflexive practices. Appetite 56(2):336-344.

Hsu, Ch.L. and M.Ch. Chen. 2014. Explaining consumer attitudes and purchase intentions toward organic food: Contributions from regulatory fit and consumer characteristics. Food Qual. Prefer. 35:6-13.

International Olive Council. 2017. World olive oil figures. 15 Dec. 2017. <http://www. internationaloliveoil.org/estaticos/view/131world-olive-oil-figures $>$.

Justin, P. and R. Jyoti. 2012. Consumer behavior and purchase intention for organic food. J. Consum. Mktg. 29(6):412-422.

Kalogeras, N., S. Valchovska, G. Baourakis, and P. Kalaitzis. 2009. Dutch consumers' willingness to pay for organic olive oil. J. Intl. Food Agribus. Mktg. 21(4):286-311.

Kesse-Guyot, E., S. Péneau, C. Méjean, F. Szabo de Edelenyi, P. Galan, S. Hercberg, and D. Lairon. 2013. Profiles of organic food consumers in a large sample of French adults: Results from the Nutrinet-Sante cohort study. PLoS One 8(10):e76998.

Kriwy, P. and R.A. Mecking. 2012. Health and environmental consciousness, costs of behaviour and the purchase of organic food. Intl. J. Consum. Stud. 36(1):30-37.

Lau, R.R., K.A. Hartman, and J.E. Ware. 1986 Health as a value: Methodological and theoretical considerations. Health Psychol. 5(1): 25-43.

Lea, E. and T. Worsley. 2005. Australians' organic food beliefs, demographics and values. Brit. Food J. 107(11):855-869.

Lernoud, J. and H. Willer. 2016. Organic agriculture worldwide: Current statistics, p. 33-116. In: H. Willer and J. Lernoud (eds.). The world of organic agriculture. Statistics and emerging trends 2016. FiBL, Frick, Switzerland.
Lindeman, M. and M. Väänänen. 2000. Measurement of ethical food choice motives. Appetite 34(1):55-59.

Lockie, S., K. Lyons, G. Lawrence, and J. Grice. 2004. Choosing organics: A path analysis of factors underlying the selection of organic food among Australian consumers'. Appetite 43(2): 135-146.

Magistris, T. and A. Gracia. 2008. The decision to buy organic food products in Southern Italy. Brit. Food J. 110(9):929-947.

Magnusson, M.K., A. Arvola, U.K. Koivisto, L. Aberj, and P.O. Sjödén. 2003. Choice of organic foods is related to perceived consequences for human health and to environmentally friendly behaviour. Appetite 40(2): 109-117.

Maloney, M.P., M.P. Ward, and G.N. Braucht. 1975. A revised scale for the measurement of ecological attitudes and knowledge. Amer. Psychol. 30(7):787-790.

Marian, L., P. Chrysochou, A. Krystallis, and J. Thogersen. 2014. The role of price as a product attribute in organic food context: An exploration based on actual purchase data. Food Qual Prefer. 37:52-60.

Michaelidou, N. and L.M. Hassan. 2008. The role of health consciousness, food safety concern and ethical identity on attitudes and intentions towards organic food. Intl. J. Consum. Stud. 32(2): $163-170$.

Minetti, A.C. 2002. Marketing de alimentos ecológicos. Ediciones Pirámide, Madrid, Spain.

Ministerio de Agricultura y Pesca, Alimentación y Medio Ambiente - MAPAMA. 2007. Plan integral de actuaciones para el fomento de la agricultura ecológica. 12 Sept. 2016. $<$ http://www.coag.org/rep_ficheros_web/ 79faf635308a44af43885329cffa94e0.pdf > .

Mulvey, M.S., J.C. Olson, R.L. Celsi, and B.A. Walker. 1994. Exploring the relationships between means-end knowledge and involvement. Adv. Consum. Res. 21(1):51-57.

Olivas, R., M. Díaz, and R. Bernabeu. 2013. Structural equation modeling of lifestyles and consumer attitudes towards organic food by income: A Spanish case study. Cienc. Investig. Agr. 40(2):265-277.

Onyango, B.M., W.K. Hallman, and A.C. Bellows. 2007. Purchasing organic food in US food systems. A study of attitudes and practice. Brit. Food J. 109(5):399-411.

Padel, S. and C. Foster. 2005. Exploring the gap between attitudes and behavior: Understanding why consumers buy or do not buy organic food. Brit. Food J. 107(8):606-625.

Padilla, C., A. Cordts, B. Schulze, and A. Spiller. 2013. Assessing determinants of organic food consumption using data from the German national nutrition survey II. Food Qual. Prefer. 28(1):60-70.

Pearson, D., J. Henryks, and H. Jones. 2011. Organic food: What we know (and do not know) about consumers. Renew. Agr. Food Syst. 26(2):171-177.

Petrescu, D.C., R.M. Petrescu-Mag, P. Burny, and H. Azadi. 2017. A new wave in Romania: Organic food. consumers' motivations, perceptions, and habits. Agroecol. Sustainable Food 41(1):46-75.

Phelps, J.E. and M.G. Hoy. 1996. The Aad-Ab-PI relationship in children: The impact of brand familiarity and measurement timing. Psychol. Mktg. 13(1):77-101.

Pino, G., A.M. Peluso, and P. Guido. 2012. Determinants of regular and occasional consumers' intentions to buy organic food. J. Consum. Aff. 46(1):157-169. 
Rezai, G., P.K. Teng, Z. Mohamed, and M.N. Shamsudin. 2012. Consumers' awareness and consumption intention towards green foods. Afr. J. Bus. Mgt. 6(12):4496-4503.

Roitner-Schobesberger, B., I. Darnhofer, S. Somsook, and C.R. Vogl. 2008. Consumer perceptions of organic foods in Bangkok, Thailand. Food Policy 33(2):112-121.

Saleki, Z.S., S.M. Seyedsaleki, and M.R. Rahimi. 2012. Organic food purchasing behaviour in Iran. Intl. J. Bus. Soc. Sci. 3(13):278-285.

Sangkumchaliang, P. and W.Ch. Huang. 2012. Consumers' perceptions and attitudes of organic food products in Northern Thailand. Intl. Food Agribus. Mgt. Rev. 15(1):87-102.

Schmid, O., G. De Fontguyon, and P. Sans. 2007. Desarrollo del mercado de productos de la agricultura ecológica en Europa: Un análisis de sus condiciones y del papel de las iniciativas comerciales. Rev. Esp. Estud. Agrosoc. Pesq. 214:15-44.

Soares, L.L.S., R. Deliza, and S.P. Oliveira. 2008. The Brazilian consumer's understanding and perceptions of organic vegetables: A focus group approach. Food Sci. Technol. (Campinas) 28(1):241-246.

Steptoe, A., T.M. Pollard, and J. Wardle. 1995. Development of a measure of the motives underlying the selection of food: The food choice questionnaire. Appetite 25(3):267-284.

Stolz, H., M. Stolze, M. Janssen, and U. Hamm. 2011. Preferences and determinants for organic, conventional and conventional-plus products - The case of occasional organic consumers. Food Qual. Prefer. 22(8):772-779.
Thogersen, J., M.D. De Barcellos, M.G. Perin, and Y.F. Zhou. 2015. Consumer buying motives and attitudes towards organic food in two emerging markets China and Brazil. Intl. Mktg. Rev. 32(3-4):389-413.

Tsakiridou, E., C. Boutsouki, Y. Zotos, and K. Mattas. 2008. Attitudes and behaviour towards organic products: An exploratory study. Intl. J. Retail Distrib. Mgt. 36(2):158-175.

Tung, S.J., Ch.Ch. Shih, S. Wei, and Y.H. Chen. 2012. Attitudinal inconsistency toward organic food in relation to purchasing intention and behavior: An illustration of Taiwan consumers. Brit. Food J. 114(7):997-1015.

Urban, J., I. Zverinová, and M. Scasný. 2012. What motivates Czech consumers to buy organic food? Sociol. Cas. 48(3):709-736.

Vanhonacker, F., E.J. Van Loo, X. Gellynck, and W. Verbeke. 2013. Flemish consumer attitudes towards more sustainable food choices. Appetite 62(1):7-16.

Van Loo, E., V. Caputo, R.M. Nayga, J.F. Meullenet, P.G. Crandall, and C.R. Steven. 2010. Effect of organic poultry purchase frequency on consumer attitudes toward organic poultry meat. J. Food Sci. 75(7):384-397.

Vecchio, R. and A. Annunziata. 2013. Consumers' attitudes towards sustainable food: A cluster analysis of Italian university students. New Medit 12(2):47-55.

Vega-Zamora, M., M. Parras-Rosa, F.J. Torres-Ruiz, and E.M. Murgado-Armenteros. 2011. Los factores impulsores e inhibidores del consumo de alimentos ecológicos en España. El caso del aceite de oliva. Interciencia 36(3):126-134.
Vega-Zamora, M., F.J. Torres-Ruiz, E.M. MurgadoArmenteros, and M. Parras-Rosa. 2014. Organic as a heuristic cue: What Spanish consumers mean by organic foods. Psychol. Mktg. 31(5): 349-359.

Verain, M.C.D., H. Dagevos, and G. Antonides. 2015. Sustainable food consumption. Product choice or curtailment? Appetite 91(1):375-384.

Vermunt, J.K. and J. Magidson. 2013. Latent GOLD 5.0 upgrade manual. Statistical Innovations Inc., Belmont, MA.

Weibel, F.P., D. Kruczynska, and D. Konopacka. 2012. Consumer preference of apple cultivars suited for organic production and which factors influence the buying decision. Acta Hort. 933: 645-652.

Willer, H. and D. Schaack. 2016. Organic farming and market development in Europe, p. 199-225. In: H. Willer and J. Lernoud (eds.). The world of organic agriculture. Statistics and emerging trends 2016. FiBL, Frick, Switzerland.

Yadav, R. and G.S. Pathak. 2016. Intention to purchase organic food among young consumers: Evidences from a developing nation. Appetite 96(1):122-128.

Yazdanpanah, M., M. Forouzani, and M. Hojjati. 2015. Willingness of Iranian young adults to eat organic foods: Application of the health belief model. Food Qual. Prefer. 41:75-83.

Zanoli, R., R. Scarpa, F. Napolitano, E. Piasentier, N. Naspetti, and V. Bruschi. 2013. Organic label as an identifier on environmentally related quality: A consumer choice experiment on beef in Italy. Renew. Agr. Food Syst. 28(1):70-79. 
Choosing food considering a healthy and balanced diet is...

Eating certain foods that help me to prevent diseases is...

Choosing foods for which I consider the possibility of recycling the container, leftovers, etc., is...

Choosing food produced without polluting the environment is...

Eating genuine, natural, non-precooked food is...

Eating safe food with the necessary guarantee of quality is...

Eating exclusive, special or gourmet foods is...

Purchasing foods that help me to maintain my weight and improve my physical appearance is...

Cooking special dishes and inviting friends for lunch or dinner is...

Purchasing foods considering their contribution to rural development, farmers' income, and increased employment is...

Purchasing foods with high sensory quality (taste, smell, appearance, texture) although

they may be more expensive than others is...

Choosing foods with as few additives as possible (preservatives, colorings or similar additives)

Using products and cooking dishes related to my tradition and my family customs is...

Using traditional products, the ones people have always had, is...

\begin{tabular}{lllll}
1 & 2 & 3 & 4 & 5 \\
1 & 2 & 3 & 4 & 5 \\
1 & 2 & 3 & 4 & 5 \\
1 & 2 & 3 & 4 & 5 \\
1 & 2 & 3 & 4 & 5 \\
1 & 2 & 3 & 4 & 5 \\
1 & 2 & 3 & 4 & 5 \\
1 & 2 & 3 & 4 & 5 \\
1 & 2 & 3 & 4 & 5 \\
1 & 2 & 3 & 4 & 5 \\
1 & 2 & 3 & 4 & 5 \\
& & & & \\
1 & 2 & 3 & 4 & 5 \\
1 & 2 & 3 & 4 & 5 \\
1 & 2 & 3 & 4 & 5 \\
\hline
\end{tabular}

Supplemental Table 2. Trust.

What is your level of confidence in the notion...

That processes and action protocols that are established by law are useful for producing organic foods

That there is rigor and absence of fraud in control and certification processes for these type of products

That the labels and logos that certify that foods have been produced using organic farming actually

show that these foods passed the required controls

That institutions that certify organic foods carry out reliable and serious checks

That the term 'organic' is accurate, i.e., that the foods actually are organic

\begin{tabular}{ccccc}
\multicolumn{5}{c}{ 1: No confidence; 5: Full confidence } \\
\hline 1 & 2 & 3 & 4 & 5 \\
1 & 2 & 3 & 4 & 5 \\
1 & 2 & 3 & 4 & 5 \\
& & & & \\
1 & 2 & 3 & 4 & 5 \\
1 & 2 & 3 & 4 & 5 \\
\hline
\end{tabular}

Supplemental Table 3. Compared beliefs.

What product do you think...

Is better quality?

Is healthier?

Has better taste?

Is safer, with lower health risks?

Has a higher sensory quality in general (better smell, better

texture, better color...)?

Respects the environment more?

Is more nutritious (with more minerals, vitamins, etc.)?

Is more natural, less manipulated and transformed?

Contains fewer chemical residues (fertilizers, herbicides...)?

Is more handmade?

Is more authentic?

Does not contain additives (preservatives, colorings, other similar additives)?

Is more useful for ill people (curative)?

Is better in most respects?

Creates more wealth for farmers?

Allows greater rural development?

Creates less chemical waste in its production?

Consumes fewer natural resources?

Is more select, "gourmet"?

Is more suitable for special situations?

Has a better appearance (packaging, label, size)?

Is more traditional?

Generates more employment for farmers?
1: Clearly the conventional product; 2 : The conventional product slightly; 3: Identical, the same; 4: The organic product slightly; 5: Clearly the organic product

\begin{tabular}{lllll}
1 & 2 & 3 & 4 & 5 \\
1 & 2 & 3 & 4 & 5 \\
1 & 2 & 3 & 4 & 5 \\
1 & 3 & 4 & 5 \\
1 & 2 & 3 & 4 & 5 \\
1 & 2 & 3 & 4 & 5 \\
1 & 2 & 4 & 5 \\
1 & 2 & 3 & 4 & 5 \\
1 & 2 & 3 & 4 & 5 \\
1 & 2 & 3 & 4 & 5 \\
1 & 2 & 3 & 4 & 5 \\
1 & 2 & 3 & 4 & \\
& 2 & 3 & 4 & 5 \\
1 & 2 & 4 & 5 \\
1 & 2 & 4 & 5 \\
1 & 2 & 3 & 5 \\
1 & 2 & 3 & 4 & 5 \\
1 & 2 & 3 & 4 & 5 \\
1 & 2 & 3 & 4 & 5 \\
1 & 2 & 3 & 4 & 5 \\
1 & 2 & 3 & 4 & 5 \\
1 & 2 & 3 & & 5 \\
1 & 2 & 3 & 4 & 5 \\
1 & 2 & & 4 & 5 \\
\hline
\end{tabular}

Supplemental Table 4. Difficulties.

I think that...

Finding organic olive oil in a shop takes more time

It is difficult to distinguish organic olive oil from other higher-quality olive oils

Non-organic olive oil is good enough for me

Organic olive oil is more difficult to find in any shop

Organic olive oil is more difficult to find than non-organic olive oil in the

shops where I usually buy food

The price difference between organic and non-organic olive oil is high
As a crucial factor in my purchase decision: 1 : it is not important at all; 5: it is very important

\begin{tabular}{lllll}
1 & 2 & 3 & 4 & 5 \\
1 & 2 & 3 & 4 & 5 \\
1 & 2 & 3 & 4 & 5 \\
1 & 2 & 3 & 4 & 5 \\
1 & 2 & 3 & 4 & 5 \\
1 & 2 & 3 & 4 & 5 \\
\hline
\end{tabular}


1: Disagree; 5 : Absolutely agree

In general, I believe that by purchasing and consuming organic virgin olive oil instead of non-organic virgin olive oil... I will take care of and will improve my health and the health of my family; I will have a healthier life and could prevent diseases

I will avoid risks associated with the consumption of chemicals (preservatives, colorings...)

I will preserve the environment with less contamination and take care of natural resources so that everyone can enjoy nature

I will consume a more authentic and traditional product, a less artificial and less manipulated product that is more reliable and has an honest label. That is to say, I will consume a traditional product

I will help rural development, create employment and improve the quality of life of farmers by generating higher income

I will consume a more specialized and select product, a higher-quality product

I will consume, in general, a product with better taste, smell, texture, color

Supplemental Table 6. Intention to purchase

In your next purchase of olive oil, how likely are you to buy organic olive oil?

Not likely

Impossible

In the near future, I intend to buy organic olive oil

\begin{tabular}{lllll}
1 & 2 & 3 & 4 & 5 \\
1 & 2 & 3 & 4 & 5 \\
1 & 2 & 3 & 4 & 5 \\
1 & 2 & 3 & 4 & 5 \\
1 & 2 & 3 & 4 & 5 \\
1 & 2 & 3 & 4 & 5 \\
1 & 2 & 3 & 4 & 5 \\
\hline
\end{tabular}

